\title{
Conurbation, Urban, and Rural Living as Determinants of Allergies and Infectious Diseases: Royal College of General Practitioners Research and Surveillance Centre Annual Report 2016-2017
}

Simon de Lusignan ${ }^{1,2}$, MD; Christopher McGee ${ }^{1,2}$, BSc (Hons); Rebecca Webb ${ }^{1}$, BSc (Hons); Mark Joy ${ }^{1}, \mathrm{PhD}$; Rachel Byford $^{1}$, BSc (Hons); Ivelina Yonova ${ }^{1,2}$, MSc; Mariya Hriskova ${ }^{1,2}, \mathrm{BSc}$; Filipa Matos Ferreira ${ }^{1}$, PhD; Alex J Elliot ${ }^{3}$, $\mathrm{PhD}$; Gillian Smith ${ }^{3}$, MBBS; Imran Rafi ${ }^{4}$, PhD

\footnotetext{
${ }^{1}$ Department of Clinical and Experimental Medicine, University of Surrey, Guildford, United Kingdom

${ }^{2}$ Royal College of General Practitioners Research and Surveillance Centre, London, United Kingdom

${ }^{3}$ Real-time Syndromic Surveillance Team, Field Service, National Infection Service, Public Health England, Birmingham, United Kingdom

${ }^{4}$ Royal College of General Practitioners Clinical Innovation and Research Centre, London, United Kingdom
}

\section{Corresponding Author:}

Simon de Lusignan, MD

Department of Clinical and Experimental Medicine

University of Surrey

Leggett Building, Daphne Jackson Road

Guildford,

United Kingdom

Phone: 44014836848002

Email: s.lusignan@ surrey.ac.uk

\begin{abstract}
Background: Living in a conurbation, urban, or rural environment is an important determinant of health. For example, conurbation and rural living is associated with increased respiratory and allergic conditions, whereas a farm or rural upbringing has been shown to be a protective factor against this.

Objective: The objective of the study was to assess differences in general practice presentations of allergic and infectious disease in those exposed to conurbation or urban living compared with rural environments.

Methods: The population was a nationally representative sample of 175 English general practices covering a population of over 1.6 million patients registered with sentinel network general practices. General practice presentation rates per 100,000 population were reported for allergic rhinitis, asthma, and infectious conditions grouped into upper and lower respiratory tract infections, urinary tract infection, and acute gastroenteritis by the UK Office for National Statistics urban-rural category. We used multivariate logistic regression adjusting for age, sex, ethnicity, deprivation, comorbidities, and smoking status, reporting odds ratios (ORs) with $95 \%$ CIs.

Results: For allergic rhinitis, the OR was 1.13 (95\% CI 1.04-1.23; $P=.003)$ for urban and $1.29(95 \%$ CI $1.19-1.41 ; P<.001)$ for conurbation compared with rural dwellers. Conurbation living was associated with a lower OR for both asthma (OR $0.70,95 \%$ CI $0.67-0.73 ; P<.001)$ and lower respiratory tract infections (OR 0.94, 95\% CI 0.90-0.98; $P=.005$ ). Compared with rural dwellers, the OR for upper respiratory tract infection was greater in urban (OR 1.06, 95\% CI 1.03-1.08; $P<.001)$ but no different in conurbation dwellers (OR 1.00, 95\% CI 0.97-1.03; $P=.93$ ). Acute gastroenteritis followed the same pattern: the OR was 1.13 $(95 \%$ CI 1.01-1.25; $P=.03)$ for urban dwellers and $1.04(95 \%$ CI $0.93-1.17 ; P=.46)$ for conurbation dwellers. The OR for urinary tract infection was lower for urban dwellers (OR 0.94, 95\% CI 0.89-0.99; $P=.02)$ but higher in conurbation dwellers (OR 1.06, 95\% CI 1.00-1.13; $P=.04)$.

Conclusions: Those living in conurbations or urban areas were more likely to consult a general practice for allergic rhinitis and upper respiratory tract infection. Both conurbation and rural living were associated with an increased risk of urinary tract infection. Living in rural areas was associated with an increased risk of asthma and lower respiratory tract infections. The data suggest that living environment may affect rates of consultations for certain conditions. Longitudinal analyses of these data would be useful in providing insights into important determinants.
\end{abstract}


(JMIR Public Health Surveill 2018;4(4):e11354) doi: 10.2196/11354

\section{KEYWORDS}

population surveillance; respiratory tract infections; conjunctivitis, allergic; asthma; urinary tract infections; gastroenteritis; healthcare disparities; socioeconomic factors; social determinants of health; medical records systems, computerized; data collection; records as topic; primary health care; general practice; infectious diseases

\section{Introduction}

\section{Urbanization as a Determinant of Health}

There is a wide range of social determinants of health. Conurbation, urban, and rural living are important among these, although their different effects are still unclear [1]. Urbanization is increasing, and the United Nations has predicted that the world urban population will double between 2007 and 2050. Urbanization is an important determinant of health [2], as it may create incubators for infectious disease [3].

Factors associated with urban and rural living contribute to differences in respiratory and allergic conditions. Pollution, climate change, and pollen exposure are all associated with increased respiratory and allergic conditions [4-6]. Farm and rural upbringing have been shown to be protective against allergic rhinitis compared with urban living [7,8]. The same gradient has been reported for asthma in northern Europe [9]. However, asthma has also been shown to have an increasing incidence with higher levels of air pollution, but there is inconsistency between age groups for specific pollutants [10,11]. Pollen levels may also be important in precipitating exacerbations of asthma [12], and there may be a complex interaction between them and with the weather [13]. Much less is known about the impact of conurbation, urban, and rural living on upper respiratory tract infection (URTI), gastroenteritis, or urinary tract infection (UTI).

The UK Royal College of General Practitioners (RCGP) Research and Surveillance Centre (RSC) is one of the oldest sentinel networks and is in its 50th season of reporting infections and respiratory conditions $[14,15]$. This is a long-standing collaboration with Public Health England [16,17]. The network is recruited to be nationally representative and, at the time of this report, comprised over 1.6 million registered patients. The network's capabilities include reporting whether patients live in a conurbation, urban, or rural area.

\section{Objective}

We carried out this study to determine whether exposure to living in a conurbation (high-density living), urban (intermediate density, such as a city or town), or rural (least dense, such as the countryside) environment was associated with more presentations to a general practice (GP) of allergic (allergic rhinitis and asthma) or common infectious conditions. This investigation is the theme of the RSC's annual report on diseases. The annual report also includes the annual weekly rates of GP presentations of all our monitored conditions (Multimedia Appendix 1).

\section{Methods}

\section{Design, Setting, and Ethical Considerations}

We extracted data from 175 volunteer GPs that are members of the RCGP RSC, with a cohort of 1,602,366 patients registered for the first 6 months of the period of April 1, 2016 to March 31,2017 . All data are pseudonymized as close to source as possible. Data were coded with Read version 2 or Clinical Terms version 3 [18]. We only extracted coded data, not free text. Disease surveillance is part of standard health service activity, so no specific ethical approval was needed. No personal identifiers are held on the RCGP RSC secure network at the University of Surrey. We did not process the data of patients who had an opt-out code (2.2\% of the RCGP RSC population).

\section{Data Preparation}

We determined a patient's urban classification by using a UK Office for National Statistics (ONS) lookup tool [19]. We did this on an individual-patient level basis using the ONS's Lower Super Output Area to estimate population density. Based on this lookup tool, if a patient's population was classified as mainly rural or largely rural, we classified them as living in a rural population. If a patient lived in an urban with significant rural, urban with city and town, or urban with minor conurbation area, we classified them as living in a city or town (referred to as rural throughout this paper). If a patient lived in an urban with major conurbation area, we classified them as living in a conurbation. These were based on the ONS Lower Super Output Area, which has a mean size in England and Wales of 1640, with population sizes ranging from 820 in South Cambridgeshire to 8250 in Oxford [20].

Our outcome variables, presentation to a GP for allergic and infectious conditions, were a composite of similar conditions grouped together, a method we adopted for the 2016-2017 annual report. To identify our outcomes, we used Read version 2 codes and Clinical Terms version 3 codes to extract the data. These codes are based on International Classification of Diseases, Tenth Revision codes. Allergic conditions were allergic rhinitis (including hay fever) and asthma. We divided infections into lower respiratory tract infections (LRTIs), comprising acute bronchitis, pneumonia, and pleurisy; URTIs, including tonsillitis, common cold, sinusitis, conjunctivitis, and otitis media; acute gastroenteritis (AGE); and UTI. We did not include influenza-like illness in this analysis, although data about these illnesses are contained in the annual report (Multimedia Appendix 1), as we plan a separate analysis taking into account vaccine exposure. Similarly, we excluded less-common conditions (eg, measles, mumps, scabies), although their weekly rates of GP presentation are included in the annual report. 
In exploring the association between living area and allergic and infectious diseases, we adjusted for age, sex, ethnicity, and socioeconomic status using the Index of Multiple Deprivation (IMD). The IMD is the official measure of relative deprivation for areas in England. It uses 7 domains of deprivation to produce an overall measure (income, employment, education, health, crime, housing and services, and living environment) [21]. We grouped these variables as follows: sex (female was the reference group); age bands (1-4 years, 5-17 years, 18-64 years, and $\geq 65$ years; the reference was $18-64$ years); ethnicity (white ethnicity was the reference; we divided the others into Asian, Black, mixed, other, and unclassified ethnicities) using an ontological approach to maximize identification [22]; and deprivation. Using the IMD, we divided deprivation into quintiles (quintile 1, most deprived, was the reference).

From the cohort of 1,602,366 patients registered, we compiled and reported data on conurbation, urban, and rural living by age, sex, ethnicity, and IMD score. We also controlled for comorbid disease. We grouped comorbidities into the following groups: 0 comorbidities (reference), 1 to 2 comorbidities, and 3 or more comorbidities. We included the following as comorbidities: depression; hypertension; chronic obstructive pulmonary disease; rheumatoid arthritis; dementia; stroke or transient ischemic attack (grouped as cerebrovascular disease); acute myocardial infarction, angina, and coronary artery disease (grouped as ischemic heart disease); congestive cardiac failure; peripheral arterial disease; chronic kidney disease; diabetes mellitus; and atrial fibrillation. We also included and controlled for smoking status in our analysis, grouping smokers into active smokers (reference), ex-smokers, nonsmokers, and unknown, based on their latest recorded smoking habit. We used these comorbidities because they are quality and outcomes framework indicators that are used to rate GP performance [23,24]. These conditions are representative of common chronic diseases and likely to be consistently recorded between practices.

\section{Statistical Analysis}

To understand whether rural, urban, or conurbation living was associated with GP presentation for certain allergic or contagious diseases, we carried out a multivariate logistic regression, with rural, urban, or conurbation as the predictor variable and disease as the outcome variable. We report the odds ratio (OR) and 95\% CI from the multivariate logistic regression [25] for conurbation, or urban compared with rural (reference). An OR greater than 1 implies greater odds of a patient living in a conurbation or an urban area presenting with the condition, and an OR of less than 1 suggests lower odds of a patient living in a conurbation or an urban area presenting with a condition, adjusting for other variables in the model. We created an aggregated table showing those conditions with significant results highlighted. Given the large number of models, we applied a Benjamini-Hochberg correction [26]. We also report probability ( $P$ value), which we calculated from the coefficients of the logistic regression.

In addition to the main effect of urban, rural, and conurbation living on GP presentation, we looked at the interaction of age band or sex and urban, rural, and conurbation living on GP presentation (see Multimedia Appendix 2 for detailed results). We also created forest plots for age bands and each of the conditions (Multimedia Appendix 3).

The analysis presented in the annual report (Multimedia Appendix 1) includes the following: (1) a map of the national distribution of RCGP RSC practices; (2) summary tables showing the conditions we monitor (median age, using horizontal box and whisker plots; sex distribution of our monitored conditions; ethnicity distribution, comparing white versus all other ethnicities; median IMD, using a horizontal box and whisker plot; and conurbation, urban, and rural distribution of our monitored conditions); and (3) weekly GP presentation rates of the conditions monitored by the RCGP RSC. Population denominators were based on the population registered in the participating practices in December. The weeks are numbered using the International Organization for Standardization system [27].

\section{Results}

\section{Population}

The RCGP RSC network population consists of 1,602,366 people. Older ( $>65$ years: $n=68,378,25.01 \%)$, less deprived (IMD score $\geq 3$ : $\mathrm{n}=274,349,25.62 \%$ ), and less ethnically mixed (white: $n=204,954,20.8 \%$; black: $n=528,1.00 \%$ ) populations live in rural areas. In comparison, younger (25-44 years: $\mathrm{n}=182,322,40.7 \%$ ), ethnically mixed (black: $\mathrm{n}=44,690,88.7 \%$; Asian: $\mathrm{n}=30,827,67.4 \%$ ), and more deprived (IMD score $<3$ : $\mathrm{n}=280,714,52.81 \%$ ) populations live in conurbations (see Multimedia Appendix 2, table B.7, and Multimedia Appendix 3, figures C.5-C.7).

\section{Main Effect}

Those living in a conurbation, in comparison with a rural area, had greater odds of presenting to a GP with allergic rhinitis (OR 1.29 , 95\% CI $1.19-1.41 ; P<.001)$ but had lower odds of presenting with asthma (OR $0.70,95 \%$ CI $0.67-0.73 ; P<.001)$ and LRTI (OR 0.94, 95\% CI 0.90-0.98; $P=.005$ ).

Those living in urban, compared with rural, areas had greater odds of presenting to a GP with allergic rhinitis (OR 1.13, 95\% CI 1.04-1.23; $P=.003$ ), URTI (OR 1.06, 95\% CI 1.03-1.08; $P<.001)$ and AGE (OR 1.13, 95\% CI 1.01-1.25; $P=.03$ ). On the other hand, urban dwellers were less likely to present to a GP with UTI (OR 0.94, 95\% CI 0.89-0.99; $P=.02$; Table 1). Figure 1 displays these main effects in more detail.

\section{Interaction Effects}

We found no interactions between sex and living area, although we did find 4 interactions for age band and living area, using rural and working age (18-64 years) as reference groups. Children aged 0 to 4 years living in urban areas were more likely to present to a GP with asthma than were adults aged 18 to 64 years living in rural areas (OR 1.42, 95\% CI 1.20-1.68; $P<.001$ ). 
Table 1. Odds ratios (ORs) and 95\% CIs of the main effect of conurbation and urban living (rural is the reference) on the 6 conditions of interest.

\begin{tabular}{|c|c|c|c|c|}
\hline \multirow[t]{2}{*}{ Conditions of interest } & \multicolumn{2}{|l|}{ Conurbation } & \multicolumn{2}{|l|}{ Urban area } \\
\hline & OR $(95 \% \mathrm{CI})$ & $P$ value $^{\mathrm{a}}$ & OR $(95 \% \mathrm{CI})$ & $P$ value $^{\mathrm{a}}$ \\
\hline Allergic rhinitis & $1.29(1.19-1.41)^{\mathrm{b}}$ & $<.001^{\mathrm{b}}$ & $1.13(1.04-1.23)^{\mathrm{b}}$ & $.003^{\mathrm{b}}$ \\
\hline Asthma & $0.70(0.67-0.73)^{\mathrm{c}}$ & $<.001^{\mathrm{c}}$ & $0.97(0.93-1.01)$ & .11 \\
\hline Lower respiratory tract infection & $0.94(0.90-0.98)^{\mathrm{c}}$ & $.005^{\mathrm{c}}$ & $1(0.96-1.04)$ & .89 \\
\hline Upper respiratory tract infection & $1(0.97-1.03)$ & .93 & $1.06(1.03-1.08)^{\mathrm{b}}$ & $<.001^{\mathrm{b}}$ \\
\hline Acute gastroenteritis & $1.04(0.93-1.17)$ & .46 & $1.13(1.01-1.25)^{\mathrm{b}}$ & $.03^{\mathrm{b}}$ \\
\hline Urinary tract infection & $1.06(1.00-1.13)^{\mathrm{b}}$ & $.04^{\mathrm{b}}$ & $0.94(0.89-0.99)^{\mathrm{c}}$ & $.02^{\mathrm{c}}$ \\
\hline
\end{tabular}

${ }^{\mathrm{a}} P$ value adjusted using Benjamini-Hochberg correction.

${ }^{\mathrm{b}} \mathrm{OR}>1$ and significant adjusted $P$ value.

${ }^{\mathrm{c}} \mathrm{OR}<1$ and significant adjusted $P$ value.

Figure 1. Forest plot showing odds ratios for various allergic and infectious diseases based on living area. AGE: acute gastroenteritis; LRTI: lower respiratory tract infection; ref: reference; URTI: upper respiratory tract infection; UTI: urinary tract infection.

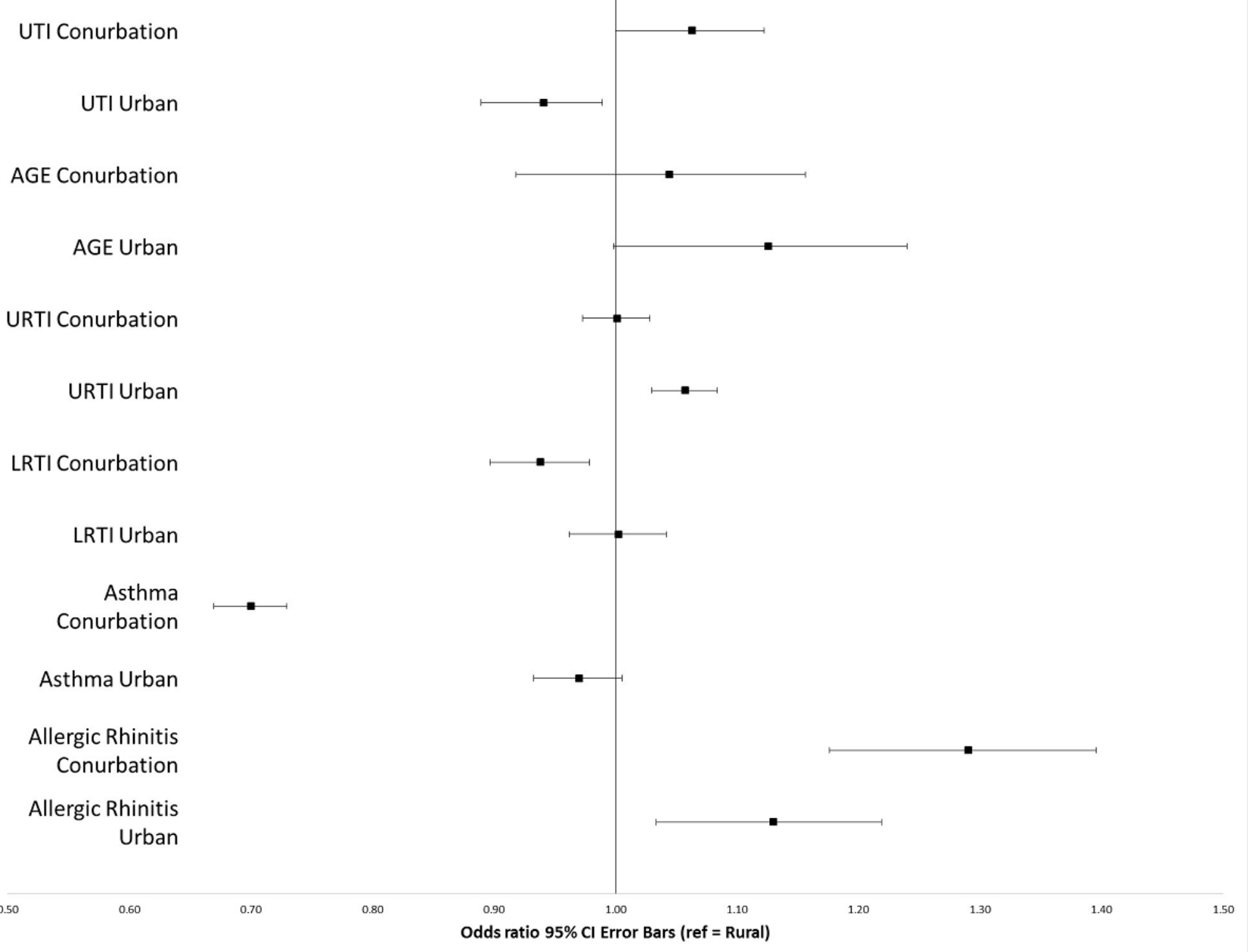

From the results of the logistic regression (Multimedia Appendix 4), we could infer the odds of children in certain areas presenting with asthma. For example, there was a $27 \%$ decrease in the odds of 0- to 4-year-olds presenting with asthma if they lived in rural compared with urban areas. Children aged between 5 and 17 years were more likely to consult for URTI than adults aged 18 to 64 years living in rural areas (OR 1.06, 95\% CI 1.02-1.11;
$P=.01)$. On the other hand, children aged 0 to 4 years living in urban areas were less likely to present with AGE than were adults aged 18 to 64 living in rural areas (OR 0.84, 95\% CI $0.72-0.98 ; P=.03)$. Over-65-year-olds living in urban areas were less likely to consult for URTI (OR $0.92,95 \%$ CI 0.88-0.97; $P<.001$ ) and AGE (OR 0.85, 95\% CI 0.72-0.99, $P=.04$ ) than was our reference group (Table 2). Children aged 0 to 4 years 
living in a conurbation were more likely to consult for URTI (OR $1.25,95 \%$ CI $1.19-1.31 ; P<.001$ ) than were 18 - to 64-year-olds living in rural areas. Children aged 5 to 17 living in conurbations were more likely to consult for asthma (OR $1.14,95 \%$ CI $1.05-1.23 ; P=.001)$, LRTI (OR 1.32, 95\% CI $1.18-1.47 ; P<.001)$, URTI (OR 1.25, 95\% CI 1.20-1.31;
$P<.001$ ), and AGE (OR 1.64, 95\% CI 1.36-1.98; $P<.001)$ than was our reference group. Additionally, those aged over 65 living in conurbations were more likely to consult for asthma (OR $1.29,95 \%$ CI $1.21-1.39 ; P<.001$ ) and LRTI (OR $1.14,95 \%$ CI $1.08-1.21 ; P<.001)$ than was our reference group (Table 3 ).

Table 2. Odds ratios (ORs) and 95\% CIs of the main effect of urban (rural is the reference) and interaction terms of urban area with age band (18-64 years is the reference) on the 6 conditions of interest.

\begin{tabular}{|c|c|c|c|c|c|c|}
\hline \multirow[t]{2}{*}{ Conditions of interest } & \multicolumn{2}{|l|}{$0-4$ years } & \multicolumn{2}{|l|}{$5-17$ years } & \multicolumn{2}{|l|}{$\geq 65$ years } \\
\hline & OR $(95 \% \mathrm{CI})$ & $P$ value $^{\mathrm{a}}$ & OR $(95 \% \mathrm{CI})$ & $P$ value $^{\mathrm{a}}$ & OR $(95 \% \mathrm{CI})$ & $P$ value $^{\mathrm{a}}$ \\
\hline Allergic rhinitis & $0.81(0.63-1.04)$ & .09 & $0.93(0.83-1.05)$ & .23 & $1.08(0.94-1.25)$ & .29 \\
\hline Asthma & $1.42(1.20-1.68)$ & $<.001$ & $1.05(0.98-1.13)$ & .18 & $0.96(0.91-1.02)$ & .18 \\
\hline Lower respiratory tract infection & $0.99(0.91-1.08)$ & .85 & $1.11(1.00-1.23)$ & .06 & $1.03(0.99-1.09)$ & .17 \\
\hline Upper respiratory tract infection & $1.03(0.99-1.08)$ & .16 & $1.06(1.02-1.11)$ & .01 & $0.92(0.88-0.97)$ & $<.001$ \\
\hline Acute gastroenteritis & $0.84(0.72-0.98)$ & .03 & $1.01(0.84-1.22)$ & .92 & $0.85(0.72-0.99)$ & .04 \\
\hline Urinary tract infection & $1.100(0.87-1.38)$ & .43 & $1(0.86-1.17)$ & .97 & $0.98(0.91-1.05)$ & .58 \\
\hline
\end{tabular}

${ }^{\mathrm{a}} P$ value adjusted using Benjamini-Hochberg correction.

Table 3. Odds ratios (ORs) and $95 \% \mathrm{CI}$ of the main effect of conurbation (rural is the reference) and interaction terms of conurbation with age band (18-64 years is the reference) on the 6 conditions of interest.

\begin{tabular}{|c|c|c|c|c|c|c|}
\hline \multirow[t]{2}{*}{ Conditions of interest } & \multicolumn{2}{|l|}{$0-4$ years } & \multicolumn{2}{|l|}{ 5-17 years } & \multicolumn{2}{|l|}{$\geq 65$ years } \\
\hline & OR $(95 \% \mathrm{CI})$ & $P$ value $^{\mathrm{a}}$ & OR $(95 \% \mathrm{CI})$ & $P$ value $^{\mathrm{a}}$ & OR $(95 \% \mathrm{CI})$ & $P$ value $^{\mathrm{a}}$ \\
\hline Allergic rhinitis & $0.84(0.65-1.07)$ & .16 & $0.94(0.83-1.05)$ & .27 & $0.99(0.85-1.17)$ & .94 \\
\hline Asthma & $1.08(0.90-1.29)$ & .43 & $1.14(1.05-1.23)$ & .001 & $1.29(1.21-1.39)$ & $<.001$ \\
\hline Lower respiratory tract infection & $0.98(0.90-1.07)$ & .68 & $1.32(1.18-1.47)$ & $<.001$ & $1.14(1.08-1.21)$ & $<.001$ \\
\hline Upper respiratory tract infection & $1.25(1.19-1.31)$ & $<.001$ & $1.25(1.20-1.31)$ & $<.001$ & $1.020 .97-1.08()$ & .40 \\
\hline Acute gastroenteritis & $0.94(0.80-1.10)$ & .45 & $1.64(1.36-1.98)$ & $<.001$ & $0.93(0.78-1.12)$ & .45 \\
\hline Urinary tract infection & $1.13(0.89-1.43)$ & .31 & $1.04(0.89-1.22)$ & .61 & $1.02(0.94-1.10)$ & .63 \\
\hline
\end{tabular}

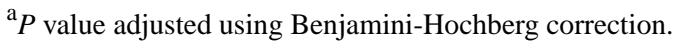

\section{Discussion}

\section{Principal Findings}

Patients living in conurbations or urban areas were more likely to consult for allergic rhinitis and URTI, after adjustment for age, sex, ethnicity, socioeconomic status, comorbid disease, and smoking status. The OR of presenting with allergic rhinitis increased with population density. While living in rural areas was associated with an increased risk of asthma and LRTI, both conurbation and rural living were associated with an increased risk of UTI.

Age and living environment interacted when predicting the GP presentation rates of these conditions. Children living in urban areas were more likely to consult for asthma (0-4 years) and URTI (5-17 years) than were 18- to 64-year-old adults living in rural areas (our reference group). Additionally, children living in conurbations were more likely than our reference groups to consult for URTI (0-17 years), LRTI, asthma, and AGE (5-17 years). Over-65-year-olds living in conurbations were also more likely than our reference group to consult for asthma. The risk of AGE was increased in 18- to 64-year-olds living in rural areas in comparison with 0 - to 4-year-olds and over-65-year-olds living in urban areas. Rural living for 18- to 64-year-olds was associated with an increased risk of URTI compared with over-65-year-olds living in rural areas.

\section{Comparison With Prior Work}

Conurbation and urban living was associated with increased presentation with allergic rhinitis to a GP. This is consistent with previous research finding that allergic rhinitis is more common in urban areas and conurbations [8,28].

Those living in conurbations had higher odds of consulting for UTI. Conurbation living is arguably very different from rural living. For example, the population density is higher [29], the nightlife is more active [30], and the levels of risky sexual behavior are higher in conurbations [31,32]. As one of the risk factors for UTIs in women is sexual intercourse [33-35], the lifestyle of conurbation living may explain this finding. However, more research is needed to test this. 
The results also showed that those living in rural areas were more likely to present with LRTI and asthma. Some studies have found that urban living is associated with increased odds of developing asthma [36], whereas others have found that rural living increases the odds [37]. Clearly more research is needed to identify environmental risk factors for developing asthma. Risk factors for LRTI vary across different studies. For example, risk factors for developing LRTI in children have been found to be pollution, poor ventilation [38], living in urban areas, and parental smoking $[39,40]$. In older people, difficulty taking medication and poor mobility were risk factors [41]. Based on these risk factors, it is difficult to understand our findings, as pollution and poor ventilation are more likely to be factors found in conurbations. However, looking at preventive factors for developing LRTI may explain the results. For example, research has found that influenza vaccination can be a protective factor against LRTI [41,42]. Furthermore, some studies have found that individuals living in rural areas are less likely to obtain preventive health services such as the influenza vaccine [43-45]. This may possibly explain our findings, although more research is needed.

Infectious diseases are associated with population density [3]; therefore, the increased odds of AGE in adults aged 18 to 64 years living in rural areas does not fit with previous research. A possible explanation may be related to food-borne illness. Risk factors for certain food poisoning-related bacteria include eating restaurant-prepared food, eating undercooked food, drinking raw milk, having contact with farm animals, and travelling abroad [46,47], factors that may be associated with rural living [48,49].

\section{Implications of the Findings}

Living in a conurbation or an urban area leads to an increased risk of allergic rhinitis and URTI in all people, and an increased risk of URTI, LRTI, asthma, and AGE in children. These results are in line with previous research, as densely populated areas have been associated with the rapid spread of infectious diseases such as the severe acute respiratory syndrome virus and avian

\section{Acknowledgments}

Thanks to the patients who consented to provide virology and other specimens in RCGP RSC practices, our member practices, Apollo Medical Systems for managing secure data extraction, Professor Mitch Blair for encouragement and support, and Nick Andrews for helpful comments on the manuscript. Requests for access to data should be addressed to SdeL, the data custodian of this study. Public Health England is the principal funder of the RCGP RSC.

\section{Authors' Contributions}

SdeL created the idea for the study, proofread the work, was director and guarantor for the data, and assisted with clinical knowledge, system design, and problem solving. CM carried out data extraction and statistical analysis for this study and the supplementary report, and drafted the introduction, methods, and results sections. RW edited the introduction, methods, and results sections, wrote the discussion, and formatted the manuscript. MJ designed the statistical analysis method. AJE and GS reviewed the manuscript. RB designed and developed much of the database structure and carried out much of the data extraction. IY and MH acted as liaison with practices and provided coordination. FMF was project manager. IR was Joint Medical Director of RCGP Clinical Innovation and Research. reduce infection spread in high-density populations.

Furthermore, population density and traffic in conurbations may increase the rates of allergic rhinitis and asthma [4-6]. Increasing the number of green spaces may be an important preventive measure [50], as they have been found to prevent higher rates of asthma [51,52] and allergic rhinitis [53,54].

\section{Strengths and Limitations}

We derived the data from a network of general practitioners in which the population in question is large and is representative of the whole of England. This large and representative ulation allows us to link morbidity to ethnicity, living this dataset can be applied to the whole population.

Further, data quality in the RCGP RSC for infections and allergic conditions is assured through data quality feedback to RSC member practices. More recently, we have introduced financially incentivized training and practice-specific comparative feedback via a dashboard [55], modelled on the principles of audit-based education [56].

The limitations of this study were that not everyone who has infectious or allergic diseases will go to their GP, meaning that population. Furthermore, although we worked hard to ensure accuracy of our data, there were instances where conditions were not recorded accurately. Additionally, the allergic conditions we investigated tend to be chronic conditions, with peaks of exacerbations. We did not control for episode type in our analysis, which may have confounded rates of GP presentation for asthma and allergic rhinitis.

\section{Conclusions}

Overall, we found that different allergic and infectious conditions were associated with rural, urban and conurbation living. A longitudinal study of RCGP RSC data may provide other variations in exposure, on the effect of the environment on allergic and infectious conditions. flu [3]. Future research should therefore focus on aiming to insights, particularly around changes in pollutant emissions or 


\section{Conflicts of Interest}

None declared.

\section{Multimedia Appendix 1}

RCGP RSC Annual Report 2016-2017.

[PDF File (Adobe PDF File), 5MB-Multimedia Appendix 1]

\section{Multimedia Appendix 2}

Data tables.

[PDF File (Adobe PDF File), 77KB-Multimedia Appendix 2]

\section{Multimedia Appendix 3}

Additional figures.

[PDF File (Adobe PDF File), 581KB-Multimedia Appendix 3]

\section{Multimedia Appendix 4}

Logistic regression output.

[PDF File (Adobe PDF File), 83KB-Multimedia Appendix 4]

\section{References}

1. Marmot M, UCL Institute of Health Equity. Review of social determinants and the health divide in the WHO European Region: final report. Copenhagen, Denmark: Regional Office for Europe, World Health Organization; 2014. URL: https:/ /tinyurl.com/haryqvi [accessed 2018-08-20] [WebCite Cache ID 71oKMZoST]

2. Alirol E, Getaz L, Stoll B, Chappuis F, Loutan L. Urbanisation and infectious diseases in a globalised world. Lancet Infect Dis 2011 Feb;11(2):131-141. [doi: 10.1016/S1473-3099(10)70223-1] [Medline: 21272793]

3. Neiderud C. How urbanization affects the epidemiology of emerging infectious diseases. Infect Ecol Epidemiol 2015;5:27060 [FREE Full text] [Medline: 26112265]

4. D'Amato G, Cecchi L. Effects of climate change on environmental factors in respiratory allergic diseases. Clin Exp Allergy 2008 Aug;38(8):1264-1274. [doi: 10.1111/j.1365-2222.2008.03033.x] [Medline: 18537982]

5. D'Amato G, Liccardi G, D'Amato M, Cazzola M. The role of outdoor air pollution and climatic changes on the rising trends in respiratory allergy. Respir Med 2001 Jul;95(7):606-611 [FREE Full text] [doi: 10.1053/rmed.2001.1112] [Medline: 11453319]

6. Vimercati L, Gatti MF, Baldassarre A, Nettis E, Favia N, Palma M, et al. Occupational exposure to urban air pollution and allergic diseases. Int J Environ Res Public Health 2015 Oct 16;12(10):12977-12987 [FREE Full text] [doi: 10.3390/ijerph121012977] [Medline: 26501303]

7. Christensen SH, Timm S, Janson C, Benediktsdóttir B, Forsberg B, Holm M, et al. A clear urban-rural gradient of allergic rhinitis in a population-based study in Northern Europe. Eur Clin Respir J 2016;3:33463 [FREE Full text] [Medline: 27890047]

8. Todkill D, Loveridge P, Elliot AJ, Morbey R, Lusignan SD, Edeghere O, et al. Socioeconomic and geographical variation in general practitioner consultations for allergic rhinitis in England, 2003-2014: an observational study. BMJ Open 2017 Aug 11;7(8):e017038 [FREE Full text] [doi: 10.1136/bmjopen-2017-017038] [Medline: 28801431]

9. Timm S, Frydenberg M, Janson C, Campbell B, Forsberg B, Gislason T, et al. The urban-rural gradient in asthma: a population-based study in northern Europe. Int J Environ Res Public Health 2015 Dec 30;13(1) [FREE Full text] [doi: 10.3390/ijerph13010093] [Medline: 26729146]

10. Anderson HR, Ponce de Leon A, Bland JM, Bower JS, Emberlin J, Strachan DP. Air pollution, pollens, and daily admissions for asthma in London 1987-92. Thorax 1998 Oct;53(10):842-848 [FREE Full text] [Medline: 10193370 ]

11. Zheng X, Ding H, Jiang L, Chen S, Zheng J, Qiu M, et al. Association between air pollutants and asthma emergency room visits and hospital admissions in time series studies: a systematic review and meta-analysis. PLoS One 2015;10(9):e0138146 [FREE Full text] [doi: 10.1371/journal.pone.0138146] [Medline: 26382947]

12. Osborne NJ, Alcock I, Wheeler BW, Hajat S, Sarran C, Clewlow Y, et al. Pollen exposure and hospitalization due to asthma exacerbations: daily time series in a European city. Int J Biometeorol 2017 Oct;61(10):1837-1848 [FREE Full text] [doi: 10.1007/s00484-017-1369-2] [Medline: 28500390]

13. Wang W. Progress in the impact of polluted meteorological conditions on the incidence of asthma. J Thorac Dis 2016 Jan;8(1):E57-E61 [FREE Full text] [doi: 10.3978/j.issn.2072-1439.2015.12.64] [Medline: 26904253] 
14. Correa A, Hinton W, McGovern A, van Vlymen J, Yonova I, Jones S, et al. Royal College of General Practitioners Research and Surveillance Centre (RCGP RSC) sentinel network: a cohort profile. BMJ Open 2016 Apr 20;6(4):e011092 [FREE Full text] [doi: 10.1136/bmjopen-2016-011092] [Medline: 27098827]

15. Elliot AJ, Fleming DM. Surveillance of influenza-like illness in England and Wales during 1966-2006. Euro Surveill 2006;11(10):249-250. [Medline: 17130657]

16. de Lusignan S, Correa A, Smith GE, Yonova I, Pebody R, Ferreira F, et al. RCGP Research and Surveillance Centre: 50 years' surveillance of influenza, infections, and respiratory conditions. Br J Gen Pract 2017 Dec;67(663):440-441 [FREE Full text] [doi: 10.3399/bjgp17X692645] [Medline: 28963401]

17. Pebody R, Warburton F, Ellis J, Andrews N, Potts A, Cottrell S, et al. End-of-season influenza vaccine effectiveness in adults and children, United Kingdom, 2016/17. Euro Surveill 2017 Nov;22(44) [FREE Full text] [doi: 10.2807/1560-7917.ES.2017.22.44.17-00306] [Medline: 29113630]

18. de Lusignan S. Codes, classifications, terminologies and nomenclatures: definition, development and application in practice. Inform Prim Care 2005;13(1):65-70 [FREE Full text] [Medline: 15949178]

19. Office for National Statistics. Guide to applying the Rural Urban Classification to data. London, UK: Office for National Statistics; 2016. URL: https://assets.publishing.service.gov.uk/government/uploads/system/uploads/attachment data/file/ 539241/Guide to applying the rural_urban_classification_to_data.pdf[WebCite Cache ID 71oLnBAI7]

20. Office for National Statistics. Postcode to output area to lower layer super output area to middle layer super output area to local authority district (December 2011) lookup in England and Wales. URL: https://tinyurl.com/ya57h749 [WebCite Cache ID 71oN4CgzR]

21. Department for Communities and Local Government. The English Indices of Deprivation 2015 - frequently asked questions (FAQs). 2016 Dec. URL: https://assets.publishing.service.gov.uk/government/uploads/system/uploads/attachment data/ file/579151/English_Indices_of_Deprivation_2015_-_Frequently_Asked_Questions_Dec_2016.pdf[WebCite Cache ID 71rjGpeLI]

22. Tippu Z, Correa A, Liyanage H, Burleigh D, McGovern A, Van Vlymen J, et al. Ethnicity recording in primary care computerised medical record systems: an ontological approach. J Innov Health Inform 2017 Mar 14;23(4):920 [FREE Full text] [Medline: $\underline{28346128}$ ]

23. National Institute for Health and Care Excellence. NICE quality and outcomes framework indicatory. 2018. URL: https:/ /www.nice.org.uk/standards-and-indicators/qofindicators[WebCite Cache ID 71rjOXi3h]

24. de Lusignan S, Mimnagh C. Breaking the first law of informatics: the quality and outcomes framework (QOF) in the dock. Inform Prim Care 2006;14(3):153-156 [FREE Full text] [Medline: 17288700]

25. Cox DR. The regression analysis of binary sequences. J R Stat Soc Ser B Methodol 1958;20:215-242 [FREE Full text]

26. McDonald JH. Multiple comparisons. In: McDonald JH, editor. Handbook of Biological Statistics. 3rd edition. Baltimore, MD: Sparky House Publishing; 2014.

27. International Organization for Standardization. ISO 8601:2004(en). Data elements and interchange formats -- information interchange -- representation of dates and times. 2004. URL: https://www.iso.org/obp/ui/\#iso:std:iso:8601:ed-3:v1:en [accessed 2018-08-20] [WebCite Cache ID 71oDdNe1u]

28. Sinha B, Vibha, Singla R, Chowdhury R. Allergic rhinitis: a neglected disease - a community based assessment among adults in Delhi. J Postgrad Med 2015;61(3):169-175 [FREE Full text] [doi: 10.4103/0022-3859.159418] [Medline: 26119436]

29. Office for National Statistics. 2011 census: population estimates by five-year age bands, and household estimates, for local authorities in the United Kingdom. 2013. URL: https://tinyurl.com/yajkxofv[WebCite Cache ID 71rjiZCd4]

30. Place I Live. 2018. Greater London URL: https://placeilive.com/[WebCite Cache ID 71rjqZsAx]

31. Dodds JP, Johnson AM, Parry JV, Mercey DE. A tale of three cities: persisting high HIV prevalence, risk behaviour and undiagnosed infection in community samples of men who have sex with men. Sex Transm Infect 2007 Aug;83(5):392-396 [FREE Full text] [doi: 10.1136/sti.2006.021782] [Medline: 17472978]

32. Chanakira E, O'Cathain A, Goyder EC, Freeman JV. Factors perceived to influence risky sexual behaviours among university students in the United Kingdom: a qualitative telephone interview study. BMC Public Health 2014 Oct 09;14:1055 [FREE Full text] [doi: 10.1186/1471-2458-14-1055] [Medline: 25300195]

33. Geerlings SE, Stolk RP, Camps MJ, Netten PM, Collet TJ, Hoepelman AI, Diabetes Women Asymptomatic Bacteriuria Utrecht Study Group. Risk factors for symptomatic urinary tract infection in women with diabetes. Diabetes Care 2000 Dec;23(12):1737-1741 [FREE Full text] [Medline: 11128343]

34. Haider G, Zehra N, Munir AA, Haider A. Risk factors of urinary tract infection in pregnancy. J Pak Med Assoc 2010 Mar;60(3):213-216 [FREE Full text] [Medline: 20225781]

35. Hu KK, Boyko EJ, Scholes D, Normand E, Chen C, Grafton J, et al. Risk factors for urinary tract infections in postmenopausal women. Arch Intern Med 2004 May 10;164(9):989-993. [doi: 10.1001/archinte.164.9.989] [Medline: 15136308]

36. Jie Y, Isa ZM, Jie X, Ju ZL, Ismail NH. Urban vs. rural factors that affect adult asthma. Rev Environ Contam Toxicol 2013;226:33-63. [doi: 10.1007/978-1-4614-6898-1 2] [Medline: 23625129]

37. Ekici A, Ekici M, Kocyigit P, Karlidag A. Prevalence of self-reported asthma in urban and rural areas of Turkey. $\mathrm{J}$ Asthma 2012 Jun;49(5):522-526. [doi: 10.3109/02770903.2012.677893] [Medline: 22502860] 
38. Savitha MR, Nandeeshwara SB, Pradeep KMJ, ul-Haque F, Raju CK. Modifiable risk factors for acute lower respiratory tract infections. Indian J Pediatr 2007 May;74(5):477-482. [Medline: 17526960]

39. Banerji A, Greenberg D, White LF, Macdonald WA, Saxton A, Thomas E, et al. Risk factors and viruses associated with hospitalization due to lower respiratory tract infections in Canadian Inuit children : a case-control study. Pediatr Infect Dis J 2009 Aug;28(8):697-701. [doi: 10.1097/INF.0b013e31819f1f89] [Medline: 19461554]

40. Ujunwa F, Ezeonu C. Risk factors for acute respiratory tract infections in under-five children in Enugu Southeast Nigeria. Ann Med Health Sci Res 2014 Jan;4(1):95-99 [FREE Full text] [doi: 10.4103/2141-9248.126610] [Medline: 24669339]

41. Loeb M, McGeer A, McArthur M, Walter S, Simor AE. Risk factors for pneumonia and other lower respiratory tract infections in elderly residents of long-term care facilities. Arch Intern Med 1999 Sep 27;159(17):2058-2064. [Medline: 10510992]

42. McDonald HI, Thomas SL, Millett ERC, Quint J, Nitsch D. Do influenza and pneumococcal vaccines prevent community-acquired respiratory infections among older people with diabetes and does this vary by chronic kidney disease? A cohort study using electronic health records. BMJ Open Diabetes Res Care 2017;5(1):e000332 [FREE Full text] [doi: 10.1136/bmjdrc-2016-000332] [Medline: 28461899]

43. O'Leary ST, Barnard J, Lockhart S, Kolasa M, Shmueli D, Dickinson LM, et al. Urban and rural differences in parental attitudes about influenza vaccination and vaccine delivery models. J Rural Health 2015;31(4):421-430. [doi:

10.1111/jrh.12119] [Medline: 25951772]

44. Sarría-Santamera A, Timoner J. Influenza vaccination in old adults in Spain. Eur J Public Health 2003 Jun;13(2):133-137. [Medline: 12803411]

45. Casey MM, Thiede CK, Klingner JM. Are rural residents less likely to obtain recommended preventive healthcare services? Am J Prev Med 2001 Oct;21(3):182-188. [Medline: 11567838]

46. Danis K, Di Renzi M, O'Neill W, Smyth B, McKeown P, Foley B, et al. Risk factors for sporadic Campylobacter infection: an all-Ireland case-control study. Euro Surveill 2009 Feb 19;14(7) [FREE Full text] [Medline: 19232225]

47. Domingues AR, Pires SM, Halasa T, Hald T. Source attribution of human salmonellosis using a meta-analysis of case-control studies of sporadic infections. Epidemiol Infect 2012 Jun;140(6):959-969. [doi: 10.1017/S0950268811002172] [Medline: 22152439]

48. Njarui DMG, Gatheru M, Wambua JM, Nguluu SN, Mwangi DM, Keya GA. Consumption patterns and preference of milk and milk products among rural and urban consumers in semi-arid Kenya. Ecol Food Nutr 2011;50(3):240-262. [doi: 10.1080/03670244.2011.568908] [Medline: 21888581]

49. Howard G, Blogh C, Goldstein G, Morgan J, Prüss A, Shaw R, et al. Healthy villages: a guide for communities and community health workers. Geneva, Switzerland: World Health Organization; 2002. URL: http://apps.who.int/iris/bitstream/ handle/10665/42456/9241545534.pdf?sequence=1\&isAllowed=y[WebCite Cache ID 73PVDCFSF]

50. Public Health England. Local action on health inequalities: improving access to green spaces. London, UK: Public Health England; 2014. URL: https://assets.publishing.service.gov.uk/government/uploads/system/uploads/attachment_data/file/ 355792/Briefing8 Green spaces health inequalities.pdf[WebCite Cache ID 71oUYlqYW]

51. Soyiri IN, Alcock I. Green spaces could reduce asthma admissions. Lancet Respir Med 2018 Dec;6(1):e1. [doi: 10.1016/S2213-2600(17)30441-1] [Medline: 29303747]

52. Feng X, Astell-Burt T. Is neighborhood green space protective against associations between child asthma, neighborhood traffic volume and perceived lack of area safety? Multilevel analysis of 4447 Australian children. Int J Environ Res Public Health 2017 Dec 19;14(5) [FREE Full text] [doi: 10.3390/ijerph14050543] [Medline: 28534841]

53. Fuertes E, Markevych I, von Berg A, Bauer C, Berdel D, Koletzko S, et al. Greenness and allergies: evidence of differential associations in two areas in Germany. J Epidemiol Community Health 2014 Aug;68(8):787-790 [RREE Full text] [doi: 10.1136/jech-2014-203903] [Medline: 24862831]

54. Ruokolainen L, von Hertzen L, Fyhrquist N, Laatikainen T, Lehtomäki J, Auvinen P, et al. Green areas around homes reduce atopic sensitization in children. Allergy 2015 Feb;70(2):195-202 [FREE Full text] [doi: 10.1111/all.12545] [Medline: 25388016]

55. Pathirannehelage S, Kumarapeli P, Byford R, Yonova I, Ferreira F, de Lusignan S. Uptake of a dashboard designed to give realtime feedback to a sentinel network about key data required for influenza vaccine effectiveness studies. Stud Health Technol Inform 2018;247:161-165. [Medline: 29677943]

56. de Lusignan S. An educational intervention, involving feedback of routinely collected computer data, to improve cardiovascular disease management in UK primary care. Methods Inf Med 2007;46(1):57-62. [Medline: 17224982]

\section{Abbreviations}

AGE: acute gastroenteritis

GP: general practice

IMD: Index of Multiple Deprivation

LRTI: lower respiratory tract infection

ONS: Office for National Statistics 
OR: odds ratio

RCGP: Royal College of General Practitioners

RSC: Research and Surveillance Centre

URTI: upper respiratory tract infection

UTI: urinary tract infection

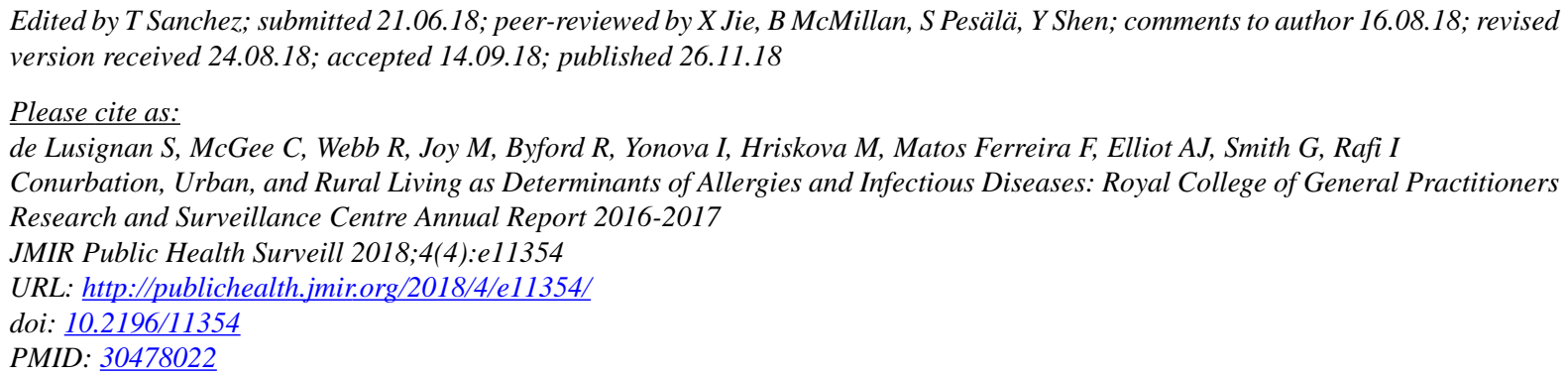

CSimon de Lusignan, Christopher McGee, Rebecca Webb, Mark Joy, Rachel Byford, Ivelina Yonova, Mariya Hriskova, Filipa Matos Ferreira, Alex J Elliot, Gillian Smith, Imran Rafi. Originally published in JMIR Public Health and Surveillance (http://publichealth.jmir.org), 26.11.2018. This is an open-access article distributed under the terms of the Creative Commons Attribution License (https://creativecommons.org/licenses/by/4.0/), which permits unrestricted use, distribution, and reproduction in any medium, provided the original work, first published in JMIR Public Health and Surveillance, is properly cited. The complete bibliographic information, a link to the original publication on http://publichealth.jmir.org, as well as this copyright and license information must be included. 